\title{
Factors associated with initiation of antihyperglycaemic medication in UK patients with newly diagnosed type 2 diabetes
}

\author{
Alan J Sinclair ${ }^{1}$, Charles M Alexander ${ }^{2}$, Michael J Davies², Changgeng Zhao ${ }^{2}$ and Panagiotis Mavros²,
}

\begin{abstract}
Aim: To assess the factors associated with antihyperglycaemic medication initiation in UK patients with newly diagnosed type 2 diabetes.

Methods: In a retrospective cohort study, patients with newly diagnosed type 2 diabetes were identified during the index period of 2003-2005. Eligible patients were $\geq 30$ years old at the date of the first observed diabetes diagnosis (referred to as index date) and had at least 2 years of follow-up medical history $(N=9,158)$. Initiation of antihyperglycaemic medication (i.e., treatment) was assessed in the 2-year period following the index date. Adjusted Cox regression models were used to examine the association between time to medication initiation and patient age and other factors.
\end{abstract}

Results: Mean (SD) $\mathrm{HbA}_{1 c}$ at diagnosis was $8.1 \%$ (2.3). Overall, 51\% of patients initiated antihyperglycaemic medication within 2 years $(65 \%, 55 \%, 46 \%$ and $40 \%$ for patients in the $30-<45,45-<65,65-<75,75+$ age groups, respectively). Among the treated patients, median $\left(25^{\text {th }}, 75^{\text {th }}\right.$ percentile) time to treatment initiation was 63 $(8,257)$ days. Of the patients with $\mathrm{HbA}_{1 c} \geq 7.5 \%$ at diagnosis, $87 \%$ initiated treatment within 2 years. These patients with a higher $\mathrm{HbA}_{1 \mathrm{c}}$ also had shorter time to treatment initiation (adjusted hazard ratio $(\mathrm{HR})=2.44[95 \%$ confidence interval (Cl): 1.61, 3.70]; $\mathrm{p}<0.0001$ ). Increasing age (in years) was negatively associated with time to treatment initiation ( $\mathrm{HR}=0.98$ [95\% Cl: 0.97, 0.99]; $\mathrm{p}<0.001$ ). Factors significantly associated with shorter time to treatment initiation included female gender and use of cardiovascular medications at baseline or initiated during follow up.

Conclusions: In this UK cohort of patients with newly diagnosed type 2 diabetes, only $51 \%$ had antihyperglycaemic medication initiated over a 2-year period following diagnosis. Older patients were significantly less likely to have been prescribed antihyperglycaemic medications. Elevated $\mathrm{HbA}_{1 \mathrm{c}}$ was the strongest factor associated with initiating antihyperglycaemic medication in these patients.

Keywords: Clinical inertia, Age, Type 2 diabetes mellitus, Antihyperglycaemic medication

\section{Background}

Management of type 2 diabetes is centered on glycaemic control, in conjunction with controlling blood pressure, cholesterol, and other cardiovascular risk factors $[1,2]$. Diabetes treatment guidelines recommend initiating treatment with antihyperglycaemic medication either concomitantly with or following a brief period of lifestyle intervention $[1,3]$. Despite these recommendations

\footnotetext{
* Correspondence: panagiotis.mavros@merck.com

${ }^{2}$ Merck Sharp \& Dohme Corp, Whitehouse Station, NJ, USA Full list of author information is available at the end of the article
}

and confirmed inadequate glycaemic control with lifestyle interventions, many patients with newly diagnosed type 2 diabetes remain untreated with antihyperglycaemic medication in clinical practice for extended periods of time [4-7]. This hyperglycaemic burden may have long-term consequences and increase the risk for both micro- and macrovascular complications of diabetes [8].

Early initiation of antihyperglycaemic medication is associated with reductions in microvascular events and long-term, legacy effects with reductions in myocardial infarction and death in patients with newly diagnosed

C Biomed Central

(c) 2012 Sinclair et al; licensee BioMed Central Ltd. This is an Open Access article distributed under the terms of the Creative Commons Attribution License (http://creativecommons.org/licenses/by/2.0), which permits unrestricted use, distribution, and reproduction in any medium, provided the original work is properly cited. 
type 2 diabetes [9-11]. Furthermore, treatment with antihyperglycaemic agents, as monotherapy, led to a 2to 3-fold increase in the proportion of patients with an $\mathrm{HbA}_{1 \mathrm{c}}<7 \%$ relative to diet alone in patients with newly diagnosed type 2 diabetes [12]. Initiation of antihyperglycaemic medication and treatment targets should be based on clinical judgment following assessment of patient factors such as age, functional status, and preexisting, co-morbid conditions and the risk of diabetes treatment-related side effects (e.g., hypoglycaemia) $[1,3,8]$. Given the increasing prevalence of type 2 diabetes in the UK [13], and the clinical benefits associated with antihyperglycaemic treatments, the present study was conducted to assess the association between patient age and initiation of antihyperglycaemic medication in UK patients following diagnosis of type 2 diabetes.

\section{Methods \\ Data Source}

The study cohort was drawn from the commerciallyavailable, widely-used Intercontinental Medical Statistics (IMS) MediPlus database [14]. This database is composed of patient information from a representative sample of general practitioners and contains records of medical encounters, prescriptions, and enrollment data for approximately 3.7 million patients in the UK and Northern Ireland.

\section{Study Design and Patient Selection}

In this retrospective analysis, patients $\geq 30$ years old with newly diagnosed type 2 diabetes were identified using International Classification of Disease (ICD)-10 codes (E11-E14) during the index period of 2003 to 2005. Newly diagnosed status was defined as having no prior diagnosis of type 2 diabetes and no prescription for antihyperglycaemic agents in the database for at least 12 months prior to the first observed diagnosis (i. e., index date). The age cut-off was chosen to minimise the likelihood of selecting a patient with type 1 diabetes. Patients included in this study were continuously active in the database for at least 1 year preceding and 2 years following the index date.

\section{Analyses}

The primary outcome was the proportion of patients who initiated antihyperglycaemic medication (also described as treatment or therapy for this analysis) during the 2-year period following the index date. Time to treatment initiation was calculated as the time between the index date and first prescription for any antihyperglycaemic agent during the follow-up period. Data were censored at 2 years of follow-up. The 2 -year follow-up period was selected to allow for sufficient time to initiate medication following guideline treatment recommendations, while also maximizing the size of the cohort, since longer follow-up periods resulted in progressively smaller cohorts. Analyses were performed on the entire cohort with age as a continuous variable and by age groups $(30-<45,45-<65,65-<75$, and $75+$ years).

Patient baseline characteristics were assessed using data from the 12 months preceding the index date. Characteristics included age at the index date, gender, and co-morbid disease conditions. Limited laboratory data are available in the MediPlus database. For the present analysis, $\mathrm{HbA}_{1 \mathrm{c}}$ values in the 6-month window centered on the index date (used as $\mathrm{HbA}_{1 \mathrm{c}}$ at diagnosis [i.e., baseline] for analysis) were identified. This window was selected to maximise the number a patients with $\mathrm{HbA}_{1 \mathrm{c}}$ values near the index date. Further, the potential 3month period beyond the index date was chosen because the full effect of any diet or exercise intervention was not likely attained within this short time period. $\mathrm{HbA}_{1 \mathrm{c}}$ values were also identified during the 6month period prior to the end of the follow up (i.e., end of study period) for all patients that were not treated with antihyperglycaemic medications at the end of the study period. The objective was to assess the association between $\mathrm{HbA}_{1 \mathrm{c}}$ values at the end of the study period and non-treatment.

Descriptive statistics (mean and standard deviations [SD] and proportions) were used for patient demographics, co-morbid conditions, and treatment characteristics. The Kaplan-Meier estimator of the survival function was used to demonstrate differences in the time to antihyperglycaemic treatment initiation across different age groups. Cox regression models were used to test for association between patient-related factors and time to initiation of antihyperglycaemic treatment adjusting for other predictors. Time-varying regression variables were included in the models to account for newly diagnosed conditions and newly prescribed (nonantihyperglycaemic) medications during the follow-up period. In the adjusted models, age was treated as a continuous variable and $\mathrm{HbA}_{1 \mathrm{c}}$ at diagnosis was treated as a categorical variable $(<7.5 \%, \geq 7.5 \%$, or missing). The $\mathrm{HbA}_{1 \mathrm{c}}$ cut point of $7.5 \%$ was selected because it is the high point of the range recommended in the UK for initiating antihyperglycaemic medication [15]. The chisquare test was used to test for significance.

\section{Results}

In the MediPlus database, 43,486 patients had a diagnosis of type 2 diabetes. Of the 11,543 who had their first observed diagnosis between 2003 and 2005, 9,158 patients (54\% male) met the inclusion criteria for this analysis. Mean (SD) age was 62.4 (12.8) years, with 9.6\%, $44.3 \%, 27.5 \%$, and $18.6 \%$ of patients within the $30-<45$, 
45- < 65, 65- < 75, 75+ age groups, respectively (Table $1) . \mathrm{HbA}_{1 \mathrm{c}}$ values were available for $55 \%(\mathrm{n} / \mathrm{N}=5,044 /$ $9,158)$ of the entire cohort. There was no association between age and missing $\mathrm{HbA}_{1 \mathrm{c}}$ values $(\mathrm{p}=0.3876$ for trend using chi-square test). Mean (SD) $\mathrm{HbA}_{1 \mathrm{c}}$ at diagnosis was $8.1 \%$ (2.3) for the cohort of patients with $\mathrm{HbA}_{1 \mathrm{c}}$ values, and 8.7\% (2.4), 8.3\% (2.3), 8.0\% (2.2), and $7.7 \%$ (2.0) for those in the 30- < 45, 45- < 65, 65- < 75, $75+$ age groups, respectively. The presence of pre-existing co-morbid conditions at baseline increased with age, except for liver disease where the opposite was observed (Table 1). During the follow-up period, newly diagnosed co-morbid conditions included cardiovascular conditions (5.7\%), microvascular complications of diabetes (7.2\%), cancer $(1.8 \%)$, edema $(1.7 \%)$, liver disease $(0.5 \%)$, and Alzheimer's disease/dementia (0.2\%). Use of antihypertensive and gastroprotective agents increased with age, whereas use of lipid-modifying agents was similar across age groups (Table 1). Newly prescribed medications during the follow-up included antihypertensive (10.1\%), lipid-modifying (28.6\%), weight-reducing (1.6\%), and gastroprotective agents $(6.3 \%)$.

Overall, 36\%, $42 \%$, and $51 \%$ of patients initiated antihyperglycaemic therapy within 180 days, 1 year, and 2 years of diagnosis, respectively. The proportion of patients who had treatment initiated within 2 years of diagnosis decreased with advancing age (65\%, 55\%, 46\%, and $40 \%$ for patients in the 30- $<45,45-<65,65-<75$, $75+$ age groups, respectively). The median time to treatment initiation increased with advancing age (213, $530,>730$, and $>730$ days for patients in the $30-<45$, $45-<65,65-<75,75+$ age groups, respectively [Figure $1])$. Among the treated patients, median $\left(25^{\text {th }}, 75^{\text {th }}\right.$ percentile) time to treatment initiation was $63(8,257)$ days, with treatment initiation increasingly delayed with age. Of the treatments prescribed, $76 \%$ of patients were prescribed metformin, $19 \%$ sulphonylurea, $4 \%$ insulin, and $1 \%$ other. Metformin use decreased with age $(77 \%$, $82 \%, 76 \%$, and $66 \%$, for patients in the $30-<45,45-<$ $65,65-<75,75+$ age groups, respectively; $\mathrm{p}<0.0001$ for trend using chi-square test) and sulphonylurea use increased with age $(15 \%, 15 \%, 22 \%$, and $32 \%$, respectively; $\mathrm{p}<0.0001$ for trend using chi-square test).

Cox regression analysis adjusting for patients' baseline characteristics showed that increasing age was associated with longer time to initiation of antihyperglycaemic medication (Table 2). An $\mathrm{HbA}_{1 \mathrm{c}} \geq 7.5 \%$ at diagnosis was associated with shorter time to treatment initiation (Table 2). In this cohort of patients (i.e., $\mathrm{HbA}_{1 \mathrm{c}} \geq 7.5 \%$ at diagnosis, $\mathrm{n}=2,446), 73 \%, 81 \%$, and $87 \%$ initiated antihyperglycaemic therapy within 180 days, 1 year, and 2 years of diagnosis, respectively. There was a significant interaction between age and $\mathrm{HbA}_{1 \mathrm{c}}$ at diagnosis such that the negative effect of age on treatment initiation was reduced in individuals with higher $\mathrm{HbA}_{1 \mathrm{c}}$ values at diagnosis, i.e., $\geq 7.5 \%$ (Table 2 ). Other significant predictors associated with shorter time to antihyperglycaemic medication initiation included female gender, use of

Table 1 Baseline characteristics of patients with newly diagnosed type 2 diabetes during the index period

\begin{tabular}{|c|c|c|c|c|c|}
\hline \multirow[t]{2}{*}{ Variable } & \multirow{2}{*}{$\begin{array}{l}\text { Entire } \\
\text { Cohort } \\
\mathrm{N}=9,158\end{array}$} & \multicolumn{4}{|c|}{ Age Group (years) } \\
\hline & & $\begin{array}{l}30 \text { to }<45 \\
\mathrm{n}=880\end{array}$ & $\begin{array}{l}45 \text { to }<65 \\
n=4,055\end{array}$ & $\begin{array}{l}65 \text { to }<75 \\
\mathrm{n}=2,522\end{array}$ & $\begin{array}{l}\geq 75 \\
n=1,701\end{array}$ \\
\hline Age, years (mean $\pm S D$ ) & $62.4 \pm 12.8$ & $38.9 \pm 4.0$ & $55.8 \pm 5.4$ & $69.3 \pm 2.8$ & $80.1 \pm 4.2$ \\
\hline Gender, male (\%) & 54 & 54 & 60 & 55 & 41 \\
\hline $\mathrm{HbA}_{1 c}$ at diagnosis, \% (mean $\pm \mathrm{SD}$ ) & $8.1 \pm 2.3$ & $8.7 \pm 2.4$ & $8.3 \pm 2.3$ & $8.0 \pm 2.2$ & $7.7 \pm 2.0$ \\
\hline Patients with $\mathrm{HbA}_{1 c}$ measurement at diagnosis, $(\mathrm{n},(\%))$ & $5,044(55.1)$ & $481(54.7)$ & $2,274(56.1)$ & $1,365(54.1)$ & $924(54.3)$ \\
\hline \multicolumn{6}{|l|}{ Patients with selected pre-existing conditions } \\
\hline Cardiovascular conditions (\%) & 19.2 & 2.5 & 13.4 & 25.4 & 32.4 \\
\hline Microvascular conditions (\%) & 1.7 & 0.5 & 1.0 & 1.8 & 3.8 \\
\hline Cancer (\%) & 4.2 & 1.3 & 2.1 & 5.6 & 8.4 \\
\hline Oedema (\%) & 2.5 & 0.6 & 2.3 & 2.7 & 3.6 \\
\hline Liver Disease (\%) & 0.6 & 1.0 & 0.6 & 0.5 & 0.2 \\
\hline Alzheimer/dementia (\%) & 0.3 & 0.0 & 0.1 & 0.3 & 1.0 \\
\hline \multicolumn{6}{|l|}{ Patients with selected medication use } \\
\hline Antihypertensive agents (\%) & 59.1 & 21.4 & 52.6 & 69.3 & 78.4 \\
\hline Lipid-modifying agents (\%) & 27.8 & 34.3 & 24.2 & 36.4 & 34.3 \\
\hline Weight-reducing agents (\%) & 1.2 & 3.2 & 1.7 & 0.5 & 0.1 \\
\hline Gastroprotective agents (\%) & 23.3 & 15.2 & 20.0 & 27.2 & 29.5 \\
\hline
\end{tabular}




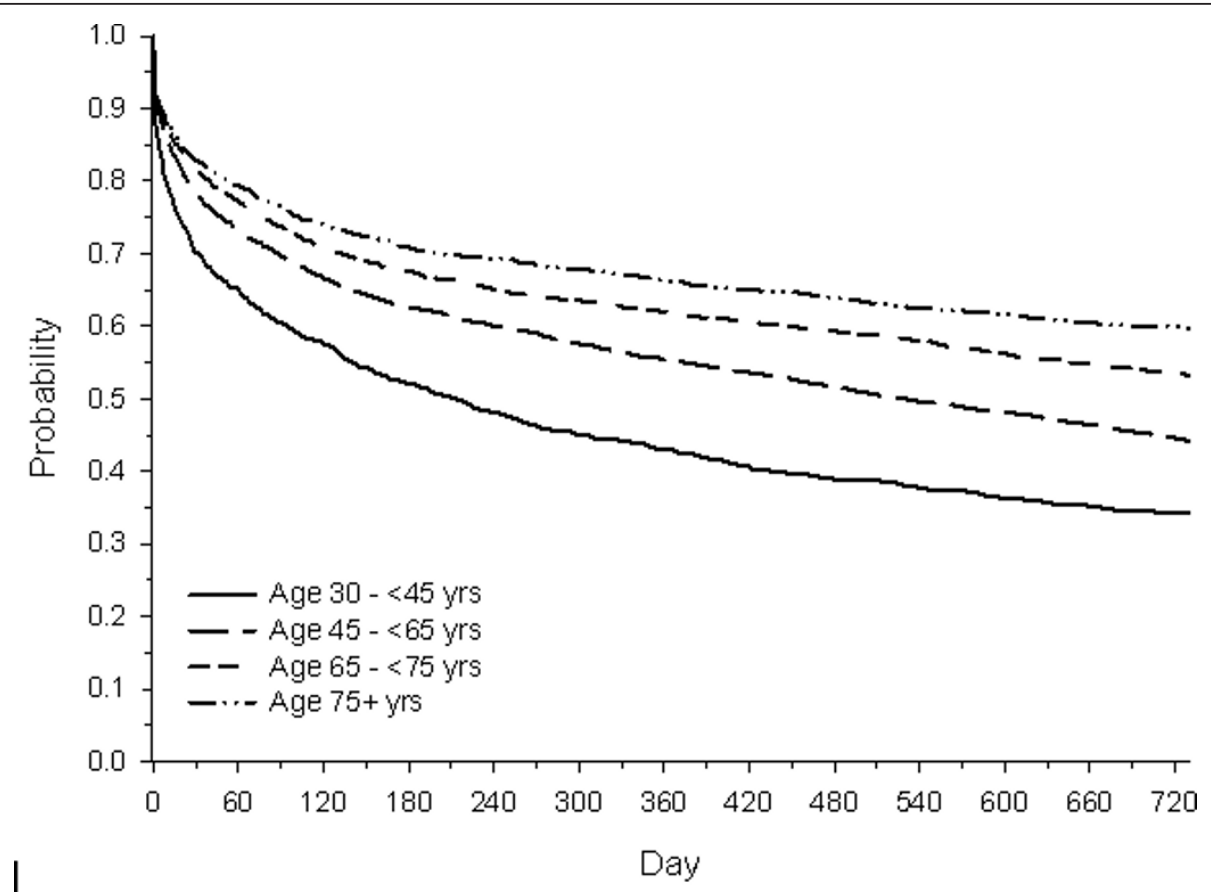

Figure 1 Kaplan-Meier curves for time to initiation of antihyperglycaemic therapy after diagnosis of type 2 diabetes by age group

lipid-modifying agents, use of weight-reducing agents and later physician registration year. The missing indicator for $\mathrm{HbA}_{1 \mathrm{c}}$ values was associated with shorter time to initiation (Table 2). During the follow-up period, development of cardiovascular conditions (Table 2), hospitalization, and new use of antihypertensive, lipid-modifying, gastroprotective, or weight-reducing agents were associated with shorter times to treatment initiation (Table 2).

Figure 2 illustrates that higher $\mathrm{HbA}_{1 \mathrm{c}}$ values at the end of follow up were associated with lower levels of non-treatment with antihyperglycaemic medications. Within each $\mathrm{HbA}_{1 \mathrm{c}}$ category there was a significant trend for patients in the older age groups to remain untreated (Figure 2). Among those untreated, the proportion of patients with an $\mathrm{HbA}_{1 \mathrm{c}} \geq 7.5 \%$ was not statistically different across age groups $(\mathrm{p}>0.05)$.

\section{Discussion}

The present study assessed the time to antihyperglycaemic medication initiation in a UK cohort of patients with newly diagnosed type 2 diabetes and found that the proportion of patients who had antihyperglycaemic therapy initiated after 2 years of follow up was $51 \%$, with lower rates of treatment initiation observed in older compared to younger individuals. This percentage is less than the $75 \%$ of Dutch patients with type 2 diabetes who initiated oral antihyperglycaemic therapy within 2 years of diagnosis [6]. In a Danish cohort, $70 \%$ of newly diagnosed diabetic patients received antihyperglycaemic therapy after nearly 6 years of follow up, despite a mean baseline $\mathrm{HbA}_{1 \mathrm{c}}$ level of 10.2\% [5]. Glycaemic control has been shown to deteriorate over time in patients with newly diagnosed type 2 diabetes, specifically those untreated with antihyperglycaemic medication (i.e., receiving only diet and lifestyle intervention) [12,16]. Therefore, given that the mean $\mathrm{HbA}_{1 \mathrm{c}}$ was $\sim 8.0 \%$ around the time of diagnosis for those with measurements and in the absence of other factors, more patients should have been initiated on antihyperglycaemic medications over the 2-year period than the $51 \%$ observed in the present study.

Although various algorithms for treatment of type 2 diabetes were in place or introduced during the time period assessed for our study (2003 - 2007), the recommendations are generally similar for patients with newly diagnosed type 2 diabetes $[15,17]$. The recommendations include language stating that lifestyle modifications should be initiated with follow-up assessment of glycaemic control (i.e., fasting glucose and $\mathrm{HbA}_{1 \mathrm{c}}$ ) within a 3 to 6 month period. If $\mathrm{HbA}_{1 \mathrm{c}}$ targets are not achieved with lifestyle modifications, initiation of antihyperglycaemic medication should be considered along with continuation of lifestyle changes. Despite such recommendations, this study demonstrated that 2 years after initial diagnosis of type 2 diabetes, a large proportion of patients remain untreated. The proportion of untreated patients was inversely related to the $\mathrm{HbA}_{1 \mathrm{c}}$ 
Table 2 Adjusted hazard ratios for initiation of antihyperglycaemic treatment

\begin{tabular}{|c|c|c|}
\hline \multirow[t]{2}{*}{ Variable } & \multicolumn{2}{|c|}{$\begin{array}{l}\text { Patient Sample } \\
\quad(\mathrm{N}=9,158)\end{array}$} \\
\hline & $\begin{array}{c}\text { Hazard Ratio }(95 \% \\
\mathrm{Cl})\end{array}$ & P-value \\
\hline \multicolumn{3}{|l|}{ Baseline $^{a}$} \\
\hline Age at first diagnosis, years & $0.98(0.97,0.99)$ & $\begin{array}{c}< \\
0.0001 \\
\end{array}$ \\
\hline $\mathrm{HbA}_{1 \mathrm{c}} \geq 7.5 \%$ & $2.44(1.61,3.70)$ & $\begin{array}{c}< \\
0.0001 \\
\end{array}$ \\
\hline Dummy $\mathrm{HbA}_{1 \mathrm{c}}($ missing $=1)$ & $1.62(1.06,2.47)$ & 0.0247 \\
\hline $\begin{array}{l}\text { Interaction: Age with } \mathrm{HbA}_{1 \mathrm{c}} \geq \\
7.5 \%\end{array}$ & $1.015(1.008,1.022)$ & $\begin{array}{c}< \\
0.0001 \\
\end{array}$ \\
\hline Gender $($ male $=1 ;$ female $=0$ ) & $0.91(0.86,0.97)$ & 0.0018 \\
\hline Physician registration years & $1.007(1.003,1.011)$ & 0.0005 \\
\hline Lipid-modifying agents & $1.22(1.12,1.32)$ & $\begin{array}{c}< \\
0.0001\end{array}$ \\
\hline Weight-reducing agents & $1.59(1.27,1.99)$ & $\begin{array}{c}< \\
0.0001\end{array}$ \\
\hline \multicolumn{3}{|l|}{ New at follow up } \\
\hline Cardiovascular conditions & $1.36(1.16,1.59)$ & 0.0001 \\
\hline Antihypertensive agents & $1.43(1.28,1.61)$ & $\begin{array}{c}< \\
0.0001\end{array}$ \\
\hline Lipid-modifying agents & $2.41(2.21,2.62)$ & $\begin{array}{c}< \\
0.0001\end{array}$ \\
\hline Gastroprotective agents & $1.59(1.36,1.88)$ & $\begin{array}{c}< \\
0.0001 \\
\end{array}$ \\
\hline Weight-reducing agents & $1.38(1.06,1.81)$ & 0.0175 \\
\hline Hospitalization & $1.37(1.22,1.54)$ & $\begin{array}{c}< \\
0.0001\end{array}$ \\
\hline
\end{tabular}

${ }^{a}$ Baseline variables assessed in 12-month period prior to diagnosis of type 2 diabetes. Non-significant predictors included in the model were indicators for baseline cardiovascular conditions, microvascular conditions, cerebrovascular conditions, cancer, liver disease, Alzheimer's disease/dementia, peptic ulcer disease, rheumatic conditions, chronic pulmonary disease, hemi- or paraplegia, oedema, antihypertensive medication use, and gastroprotective medication use, and indicators for follow-up microvascular conditions, cancer, oedema, liver disease and Alzheimer's disease/dementia.

values with a greater proportion of patients receiving treatment as $\mathrm{HbA}_{1 \mathrm{c}}$ increased. However, $30 \%$ of patients with an $\mathrm{HbA}_{1 \mathrm{c}}$ value $\geq 7.5 \%$ at the end of follow up had not yet received treatment, despite the apparent need for treatment based on guidelines.

Management of type 2 diabetes is related to a myriad of patient-, physician, and systematic-related factors [18]. Patient age may affect treatment initiation or intensification and limit treatment choices because of the increased likelihood of co-morbidities and frailty in older patients [19]. In the present study older patients were more likely to have pre-existing, co-morbid conditions. After adjusting for these differences, increasing age was still associated with a decreased likelihood of physician prescribing of antihyperglycaemic medication. Similar findings were found with a US cohort of patient with newly diagnosed type 2 diabetes [20]. Conversely, higher $\mathrm{HbA}_{1 \mathrm{c}}$ values near the time of diagnosis increased the likelihood of a physician initiating antihyperglycaemic medication. Younger patients had higher $\mathrm{HbA}_{1 \mathrm{c}}$ at diagnosis, which account for part of the higher rates of treatment initiation relative to older patients. When controlling for $\mathrm{HbA}_{1 \mathrm{c}}$ values at diagnosis, older patients were less likely to initiate treatment than younger patients. However, a significant interaction was observed between age and $\mathrm{HbA}_{1 \mathrm{c}}$ values $\geq 7.5 \%$ at diagnosis, suggesting that the influence of age on non-treatment with antihyperglycaemic medication was reduced as $\mathrm{HbA}_{1 \mathrm{c}}$ increased above $7.5 \%$. Similar trends were observed when $\mathrm{HbA}_{1 \mathrm{c}}$ at the end of follow up was used in the analysis. It is apparent that older patients in this study were not treated as frequently with antihyperglycaemic therapy as younger patients with the same $\mathrm{HbA}_{1 \mathrm{c}}$ level. A recent survey study evaluated the reasons UK general practitioners do not treat their newly diagnosed type 2 diabetes patients with antihyperglycaemic medications. Reasons cited by the general practitioners were those related to adequate glycaemic control for both younger and older patients. However, issues related to safety of antihyperglycaemic agents, burden to the patients, or cognitive or physical function of the patient were selected more often by GPs for not treating their older patients [21]. Collectively, the present findings are consistent with the less stringent, glycaemic target recommendations for older adults, especially those with pre-existing, co-morbid conditions [22].

In addition, the development or treatment of co-morbid conditions during the follow-up period was positively associated with initiating antihyperglycaemic treatment. The new conditions may have prompted the physician to evaluate glycaemic control in the context of increased risk factors for cardiovascular disease, as recommended by treatment guidelines $[1,15]$. Of the patients who initiated treatment, median time to start treatment was approximately 2 months. This is consistent with clinical guidelines in place at the time (2003 2007) that suggested initiating antihyperglycaemic treatment if inadequate glycaemic control was present after a short period (3 to 6 months) of lifestyle intervention $[15,17]$.

These limitations should be considered when interpreting the present results. $\mathrm{HbA}_{1 \mathrm{c}}$ measures around the time of diagnosis were available for only $55 \%$ of the patients. Thus, the $\mathrm{HbA}_{1 \mathrm{c}}$ results may not reflect the true baseline value at the time of diagnosis for the entire cohort. The study had only a 2 -year follow-up period. If one more year of follow up was added, the patient count would have been reduced by $15-30 \%$. Although eligible patients had to be at least 30 years old and were identified using ICD-10 codes for type 2 diabetes, some 


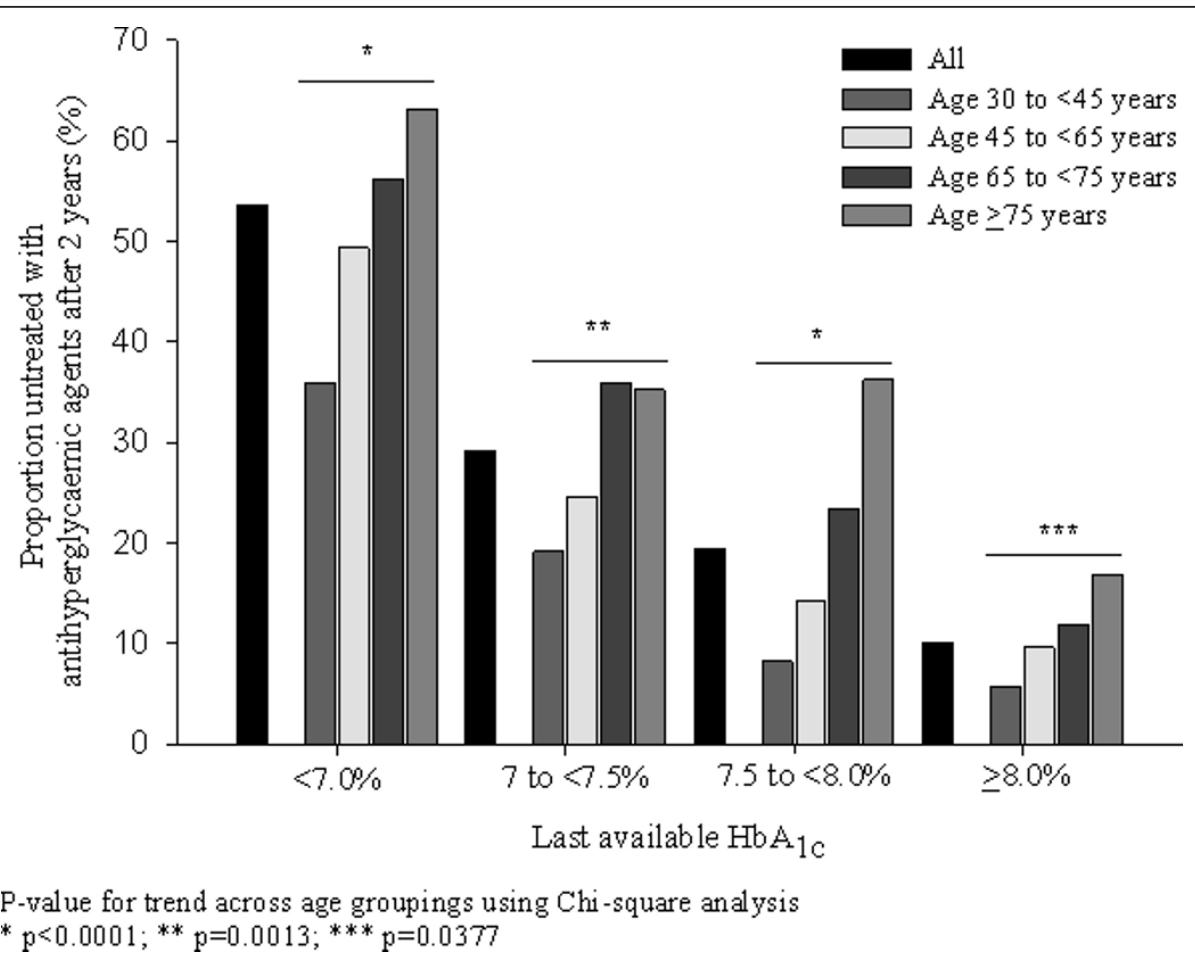

Figure 2 Proportion of patients untreated with antihyperglycaemic medication after the 2-year follow-up period by age group and last available $\mathrm{HbA}_{1 \mathrm{c}}$ value.

patients with type 1 diabetes may have been incorrectly indentified as having type 2 diabetes, although the number is likely to have been small.

In summary, in this UK cohort of patients with newly diagnosed type 2 diabetes, only $51 \%$ had antihyperglycaemic medication initiated over a 2 -year period following diagnosis, with older patients significantly less likely to have been prescribed medication by their physicians. Elevated $\mathrm{HbA}_{1 \mathrm{c}}$ was the strongest factor associated with initiating antihyperglycaemic medication in these patients. These results highlight the under-treatment of older adults with type 2 diabetes. Further research is needed to better understand the reasons for the observed differences between younger and older patients with type 2 diabetes.

\section{Acknowledgements}

The study was funded by Merck Sharp \& Dohme, Corp., a subsidiary of Merck and Co., Inc., Whitehouse Station, NJ.

\section{Author details}

${ }^{1}$ Beds \& Herts Postgraduate Medical School, Luton, UK. ${ }^{2}$ Merck Sharp \& Dohme Corp, Whitehouse Station, NJ, USA. ${ }^{3}$ Global Health Outcomes, Merck Sharp \& Dohme Corp, Mail: WS2E76, 1 Merck Drive, Whitehouse Station, NJ 08889, USA.

\section{Authors' contributions}

AJS, CMA, CZ, and PM were involved in the concept and design of the study. CZ and PM were involved in the data collection and/or analysis. All authors were involved in interpretation of the results. MJD and PM drafted the article and all authors were involved in the critical revision and approval of the article.

\section{Competing interests}

CMA, MJD, CZ, and PM are employees of Merck Sharp \& Dohme, Corp. AJS has no conflict of interest related to this analysis.

Received: 13 May 2011 Accepted: 7 March 2012

Published: 7 March 2012

\section{References}

1. National Collaborating Centre for Chronic Conditions: Type 2 diabetes: National clinical guideline for management in primary and secondary care (update) London: Royal College of Physicians; 2008.

2. American Diabetes Association: Standards of medical care in diabetes2011. Diabetes Care 2011, 34(1):S11-S61.

3. Nathan DM, Buse JB, Davidson MB, Ferrannini E, Holman RR, Sherwin R, et al: Medical management of hyperglycaemia in type 2 diabetes mellitus: a consensus algorithm for the initiation and adjustment of therapy: a consensus statement from the American Diabetes Association and the European Association for the Study of Diabetes. Diabetologia 2009, 52:17-30

4. Olivarius $\mathrm{N}$, Andreasen $\mathrm{AH}$, Siersma $\mathrm{V}$, Richelsen $\mathrm{B}$, Beck-Nielsen $\mathrm{H}$ : Changes in patient weight and the impact of antidiabetic therapy during the first 5 years after diagnosis of diabetes mellitus. Diabetologia 2006, 49:2058-2067.

5. Olivarius $N$, Beck-Nielsen $H$, Andreasen AH, Horder M, Pedersen PA: Randomised controlled trial of structured personal care of type 2 diabetes mellitus. BMJ 2001, 323:970-975.

6. Spoelstra JA, Stolk RP, Klungel OH, Erkens JA, Rutten GE, Leufkens HG, et al: Initiation of glucose-lowering therapy in Type 2 diabetes mellitus patients in general practice. Diabet Med 2004, 21:896-900.

7. Davies MJ, Heller S, Skinner TC, Campbell MJ, Carey ME, Cradock S, et al: Effectiveness of the diabetes education and self management for ongoing and newly diagnosed (DESMOND) programme for people with 
newly diagnosed type 2 diabetes: cluster randomised controlled trial. BMJ 2008, 336:491-495.

8. Del Prato S, Penno G, Miccoli R: Changing the treatment paradigm for type 2 diabetes. Diabetes Care 2009, 32(2):S217-S222.

9. UK Prospective Diabetes Study (UKPDS) Group: Intensive blood-glucose control with sulphonylureas or insulin compared with conventional treatment and risk of complications in patients with type 2 diabetes (UKPDS 33). Lancet 1998, 352:837-853.

10. UK Prospective Diabetes Study (UKPDS) Group: Effect of intensive bloodglucose control with metformin on complications in overweight patients with type 2 diabetes (UKPDS 34). Lancet 1998, 352:854-865.

11. Holman RR, Paul SK, Bethel MA, Matthews DR, Neil HA: 10-year follow-up of intensive glucose control in type 2 diabetes. N Engl J Med 2008, 359:1577-1589.

12. Turner RC, Cull CA, Frighi V, Holman RR: Glycemic control with diet, sulfonylurea, metformin, or insulin in patients with type 2 diabetes mellitus: progressive requirement for multiple therapies (UKPDS 49). JAMA 1999, 281:2005-2012.

13. Diabetes in the UK 2010: Key statistics on diabetes. [http://www.diabetes. org.uk/Documents/Reports/Diabetes_in_the_UK_2010.pdf.].

14. Lawrenson R, Coles G, Walton K, Farmer R: Characteristics of practices contributing to the MediPlus database and the implications for its use in epidemiological research. J Inform Prim Care 1998, 1:14-18.

15. National Collaborating Centre for Chronic Conditions: Management of type 2 diabetes: Managing blood glucose levels London: Royal College of Physicians; 2002.

16. Esposito K, Maiorino Ml, Ciotola M, Di Palo C, Scognamiglio P, Gicchino M, et al: Effects of a Mediterranean-style diet on the need for antihyperglycemic drug therapy in patients with newly diagnosed type 2 diabetes: a randomized trial. Ann Intern Med 2009, 151:306-314.

17. Nathan DM, Buse JB, Davidson MB, Heine RJ, Holman RR, Sherwin R, et al: Management of hyperglycemia in type 2 diabetes: A consensus algorithm for the initiation and adjustment of therapy: a consensus statement from the American Diabetes Association and the European Association for the Study of Diabetes. Diabetes Care 2006, 29:1963-1972.

18. Brown JB, Harris SB, Webster-Bogaert S, Wetmore S, Faulds C, Stewart M: The role of patient, physician and systemic factors in the management of type 2 diabetes mellitus. Fam Pract 2002, 19:344-349.

19. Spain M, Edlund BJ: Pharmacological management of type 2 diabetes in newly diagnosed older adults. J Gerontol Nurs 2009, 35:16-21.

20. Zhang Q, Rajagopalan S, Marrett E, Davies MJ, Radican L, Engel SS: Time to treatment initiation with oral antihyperglycaemic therapy in US patients with newly diagnosed type 2 diabetes. Diabetes Obes Metab 2012, 14:149-154.

21. Zhang Q, Marrett E, Jameson K, Meiler S, Davies MJ, Radican L, et al: Reasons given by general practitioners for non-treatment decisions in younger and older patients with newly diagnosed type 2 diabetes mellitus in the United Kingdom: A survey study. BMC Endocrine Disorders 2011, 11:17.

22. Brown AF, Mangione CM, Saliba D, Sarkisian CA: Guidelines for improving the care of the older person with diabetes mellitus. J Am Geriatr Soc 2003, 51:S265-5280.

Pre-publication history

The pre-publication history for this paper can be accessed here: http://www.biomedcentral.com/1472-6823/12/1/prepub

doi:10.1186/1472-6823-12-1

Cite this article as: Sinclair et al.: Factors associated with initiation of antihyperglycaemic medication in UK patients with newly diagnosed type 2 diabetes. BMC Endocrine Disorders 2012 12:1

\section{Submit your next manuscript to BioMed Central and take full advantage of:}

- Convenient online submission

- Thorough peer review

- No space constraints or color figure charges

- Immediate publication on acceptance

- Inclusion in PubMed, CAS, Scopus and Google Scholar

- Research which is freely available for redistribution

Submit your manuscript at www.biomedcentral.com/submit
Biomed Central 